\title{
China's present situation and developing trend of biological
}

\section{pharmaceutical industry research}

\author{
WeiLong $^{1}$, JipingWei ${ }^{2}$, HaisongYin ${ }^{3}$, ZhihengPan $^{4}$ \\ 1,2,3,4 Tinjin Modern Vocational Technology College, Tianjin, China, 300350
}

\begin{abstract}
Key words: Biological Pharmaceutical, Present Situation, Development Trend
\end{abstract}
\begin{abstract}
: the biological pharmaceutical industry is a sun-rising industry, broad prospects for many countries are planning as its key domestic development, biological pharmaceutical industry will become the future of world science and technology and economic competition strategic high ground. This article more comprehensively introduces the research progress of biological pharmaceutical industry in China, discussed the existing problems in biomedical research in China, a certain amount of settlement, and proposed.
\end{abstract}

\section{The Progressing Research In Biological Pharmaceutical In Our Country}

Biochemical drugs refers to the biological chemistry, on the basis of research results, using organisms play an important role in all kinds of basic material, through some means such as extraction, separation and purification of developed bioactive substances, such as amino acids, peptides, proteins, enzymes, coenzyme, grease, polysaccharide, nucleotides and biogenic amine, etc., and their derived structure[3], at present our country has been on the study of biochemical drugs have a certain progress: in inhibiting tumor growth, resisting thrombosis, cerebral hemorrhage clinical application, resist fatigue, in the treatment of osteoarthritis, etc have gained some research success [4,5].

Dong He etc. [6] sitosterol from hawthorn extract and appraisal, and to three kinds of tumor cells in logarithmic phase (Heps, S180 and EAC) and one kind of human normal liver cells (L02) the MIT proliferation and DNA gel electrophoresis experiments, the role of research sitosterol in these four cells. Gel electrophoresis results: no DNA ladder with blank control group, the other three groups are different levels of DNA ladder belt, showed the characteristics of cell apoptosis. The experiment results show that: a certain concentration of sitosterol in vitro culture of Heps, S180 and EAC cells have the effect of the inhibition, no obvious inhibitory effect to the body's cells. Thus draw the conclusion: sitosterol is probably by promoting tumor cell apoptosis to curb its breeding, further verify the function of plant sitosterol has antitumor[7].

Genetic engineering drugs production is generally determined by the first of a disease prevention and treatment effect of protein, then using restriction enzymes and exogenous gene from the control of the process of protein synthesis genes, again through DNA ligase and gene carrier (plasmid, bacteriophages, viruses) DNA, connection, and then turn to microorganisms or cells for cloning, and makes the purpose gene eventually successful expression within the host cell, achieve the desired protein [8].

The first generation of genetic engineering drugs mainly for lack of natural endogenous protein caused by disease, application of genetic engineering technology to expand the production of this kind of polypeptide protein to replace or supplement the body's need for this type of active polypeptide protein. Is the second type of genetic engineering drugs according to the physiological 
activity of endogenous peptide protein, application of genetic engineering these extremely rare material in mass production and supply of human body, super normal concentration dose so as to stimulate their active natural as its pharmacological basis for the treatment of disease[1].

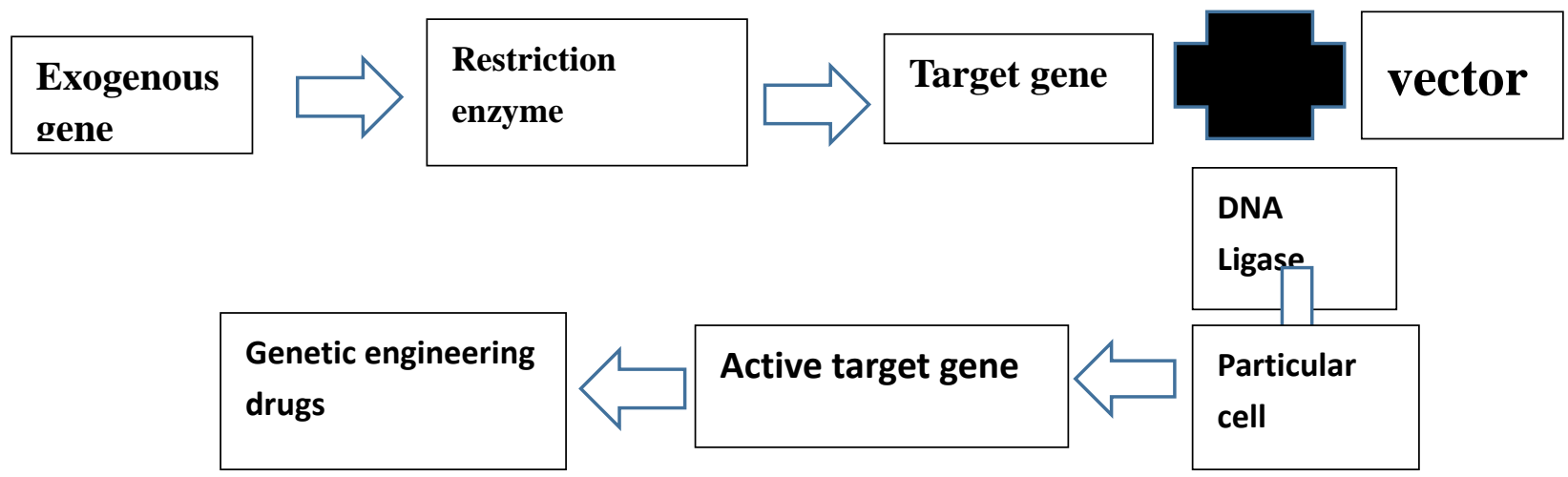

Fig 1 the manufacture of genetic engineering drugs

Interferon is an important example of our country has launched the research to its, interferon has a broad spectrum antiviral efficacy, is an effective drug for treatment of hepatitis b. Was the only internationally approved drugs for the treatment of viral hepatitis c. However, only in the event of a virus infection or induced by interferon inducer, interferon gene can express in the human body produce interferon, and few (even after the induction, $8000 \mathrm{ml}$ of blood can only extract $1 \mathrm{mg}$ interferon, cost). Through genetic engineering, by contrast, can be efficiently mass-produced interferon, the advantage of genetic engineering drugs on this point is very clear[11].

Cell therapy and gene therapy are also is one of the direction of the rapid development of our country, xiao-li li [12] and so on diabetic rats model, to observe the pancreatic high quality peptide 1 gene (hGLP - 1) analogues ( $2 \times$ Val2 - hGLP - 1) the influence of the body's metabolism in diabetic rats models. After treatment of diabetic rats weight, eating and drinking to improve significantly.

Cell engineering drugs is cell engineering technology in the application of the pharmaceutical industry. Cell engineering is according to the principle of cell biology and engineering, directional change of genetic material in the cell to gain new biological product of a technical or special cells. The research of this technology in the biological pharmaceutical plays an irreplaceable role in the world biotech drugs used in the animal cell engineering has been more than eighty percent of production, such as proteins, monoclonal antibodies, vaccines, etc[12]. The application of plant cell engineering embodied in large-scale plant cell culture to produce medicinal ingredients and two aspects of the transgenic plants producing drugs[13], at the same time, plant bioreactor has started to develop in the field of foreign bio-pharmaceutical, and take a certain success, and domestic also is valued gradually[14].

At present our country in cell fusion, nuclear transplantation, plant drugs, has obtained the certain research results extract, etc. With the development of the mammary gland bioreactor is one of the most promising a cell engineering pharmaceutical direction[15]. As early as 2005 in our country have launched research: in 2005, China agricultural university, led by professor li ning "efficient expression of human lactoferrin medical care protein cow mammary gland bioreactor" project team after four years of effort, for the first time in the world using somatic cell cloning technology to obtain human lactoferrin transgenic cattle and alpha genetically modified cattle serum albumin, which human lactoferrin transgenic cattle express amount reached 34 grams per liter. Alpha - genetically modified cattle serum albumin to obtain the expression of 15 grams per litre, close to international advanced level, and have the same as the natural protein biological activity. 


\section{The problems existing in the domestic biological pharmaceutical industry}

Although after years of development, biological pharmaceutical industry in China has had great progress, but due to the biological pharmaceutical industry itself high pharmaceutical industry also faces many problems, and the level of developed countries still have larger gap.

Mainly manifested in the following aspects:

So far, although China has more than 200 engaged in biopharmaceutical companies, but most of these companies on a smaller scale, mostly some private enterprises and foreign enterprises, unable to compete with international giants, in addition, the markets into homogeneous competition, on the other hand, although these companies all in the name of biopharmaceutical biological drugs in actual production of the whole pharmaceutical industry share of about seven point three six percent, far below the global biological pharmaceutical industry in the proportion of the pharmaceutical industry[3].

Developed countries invest a lot of money each year for biopharmaceutical research and development and production, compared with investment in China is far from enough. In addition, from the perspective of patent application for the production of the United States, Europe and other developed countries and regions, the application of biotechnology can reach more than fifty percent of all patents, patent and patent application of biotechnology in China less than one percent of the total patent. In addition, due to the lack of core technology in biological pharmaceutical, not yet a have obvious advantages in technology and market of product, new biological pharmaceutical enterprise is still in the stage of low level repeated construction.

Biopharmaceutical industry development, there are some deep and long-lasting platform construction and the construction of environment problems. Such as domestic capital market is imperfect, single creature as long as technology enterprises financing channels, financing difficulties, limiting the biological pharmaceutical enterprise's capital investment; Low conversion rate of scientific and technological achievements, research and development of new technology cannot be quickly put into practical use; Patent protection does not reach the designated position, biomedical field impetuous style is serious; Now, drug very bidding mechanism, circulation system not to adapt to the rapid development of biological pharmaceutical industry, etc. All of these problems are related to biological medicine system platform construction level is insufficient, all restricted me sad biological pharmaceutical industry sustained, healthy and rapid development ${ }^{[5.6]}$.

\section{Biopharmaceutical Development Momentum}

We can from clinical trials or declare stage of biotech drugs, has been approved for listing of biotech drugs and annual sales of biotech drugs in biopharmaceutical industry the proportion changes seen momentum of development.

Biotech drugs very steady and healthy development, according to the unity of the IMS data, by the end of February 2003, the United States, the European Union and Japan, about 500 kinds of biotech drugs in clinical trials or declaration phase, accounted for twenty-seven percent of the total drug clinical trials (figure 4). In the research of biotech drugs, in addition to gene recombinant protein products, and nucleic acid products has entered the second phase or phase iii clinical trials, has good prospects for development. Research and development of high speed growth and biotech drugs is stable proportion of successful listing, makes the proportion of biotech drugs in the pharmaceutical industry is more and more big. 


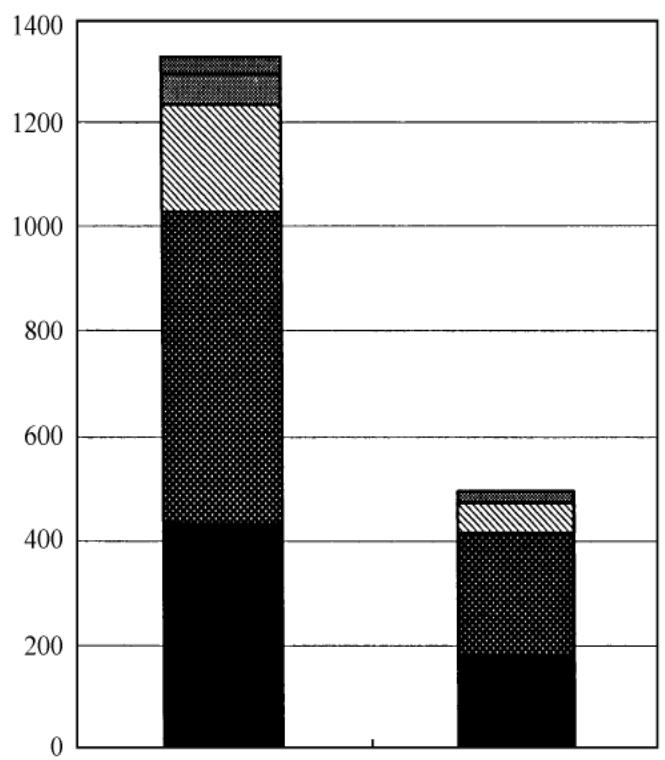

The biotech drugs Biotech drugs

Fig.2 At different development stages of the drug (In February, 2003)

Innovative drug is refers to the molecular structure is different from any previous drug drugs (not a change in dosage form). For example, the first approval of any Rituxan (1997), Enbrel (1998), etc. Innovative drugs, but in 1999, 2000, 2003, in 2004 the FDA approved Enbrel statistics in innovative drugs. As another example, the FDA approved by Schering Plough Rebetron company, which is used in the manufacturing of hepatitis c treatment (virus before and restructuring A interferon combination), due to its two ingredients are already approed medicines, not as A innovative drugs, but in 2001 approved the company's production of PEG A PEG interferon exon), due to the molecular structure has changed, shall be deemed to be innovative drugs. According to the standard statistical FDA approval of innovative drugs in recent 10 years (figure 5), it can be seen that the FDA approval of small molecule drugs since 1996 had gradually decline, from your 53 in 1996 dropped to 17 in 2002. According to the association of the United States as long as, in the past ten years the FDA approved drugs, due to the complexity of biotech drugs in clinical trials, hindered the speed of biotech drugs listed. But even so, the development of biotech drugs is still relatively smooth, from 1996 to 1996, and every year, about five to nine innovative biotech drugs listed (figure 5). In 2002 the FDA approved drugs, biotech drugs have accounted for more than three times of innovative drugs.

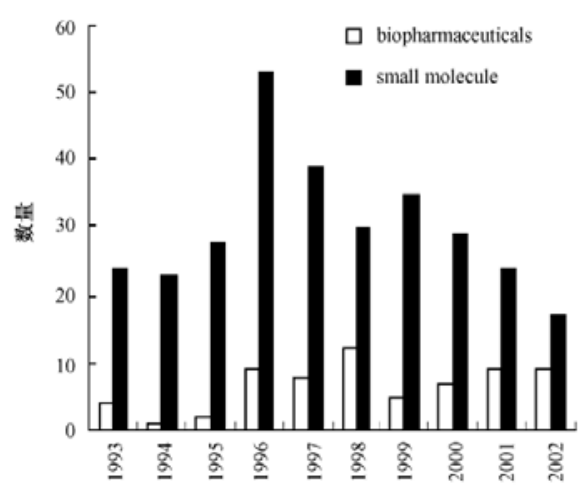

Fig.3 The FDA approved annual innovation drugs 


\section{Suggestions for the development of biopharmaceutical industry in China}

The needs of the society, the positive policy, state the importance of biological pharmaceutical products become the future prospects for development, one of the larger industries growth space. Biological pharmaceutical enterprises in China are often on the basis of the previous development, from the following several aspects to obtain, in the \"twelfth five-yearl" period to fulfill the goals of the biotech pharmaceutical high.

There are a large number of scientific research talents in Chinese universities and research institutes engaged in biomedical research and development work, but a large part of the industrialization of research results and can't, and biopharmaceutical companies due to restricted by various conditions, its own research and development level, there is still a gap compared with universities, research institutes, urgently needs to realize the industrialization of research results. Therefore, both can according to their own characteristics, then a kind of colleges and enterprises to gain access to new technology and human resources and capital investment in common measures, for colleges and universities and the enterprise is a win-win mechanism. First of all, the enterprise can get more with less input may have knowledge of the market value; Secondly, colleges and universities have the advantages of the knowledge of nuclear technology, on the basis of available research funding support from enterprises, to strengthen the ability to grasp the market and technology commercialization. But in the process of this cooperation, should be to join the strict supervision mechanism, avoid the loss of state funding improper cooperation or excessive commercialization of colleges and universities.

For change based products enterprises small in scale, overcapacity, high-end products in short supply, the current situation of the industry as a whole big and not strong, accelerate the industry consolidation, mergers, restructuring and weak competitive enterprises, enhance the core competition of the industry as a whole, we must accelerate industrial upgrading. Industrial upgrading is to point to the improvement of the industrial structure and industrial quality and efficiency, the core is to transform traditional industries with advanced and practical technology. In the pharmaceutical industry contains three meanings: the first is the upgrading of products, from the active pharmaceutical ingredients and generic drugs as the main product model to have independent intellectual property rights of innovative medicine pattern transformation. On new drug examination and approval, therefore, regulators can speed up the examination and approval of new drugs, raise the threshold of the new drug created at the same time, let the real innovation medicine for examination and approval, and obtain the corresponding price advantage, ensure enterprise huge r\&d to get the corresponding returns. , of course, completely after all is difficult and high cost of innovation, policy should also encourage enterprises to upgrade the dosage form innovation, innovation of application results, and improve the level of the entire product manufacturing, which are all belong to the category of the concept of industrial upgrading. The second is the upgrading of product standards, for the effectiveness of the drug, security should have higher requirements. The third is the upgrading of quality assurance system, is put forward for the whole production system, the whole enterprise quality assurance goals. For example, the new "drug production quality management norms" (GMP) covers the eu GMP, this will greatly improve the quality assurance system; At the same time the implementation of the new specification will make some lack of competitiveness of small enterprise in the market, accelerate the process of industrial upgrading. In addition, the high-level personnel is the key to industrial upgrading, you can attract the foreign work in the new drug research and development of Chinese scientists and scholars engaged in research and development work, will be able to directly promote enterprise's development.

Patent strategy, which refers to the enterprise starting from the long-term strategic objectives, 
fully effective use of patent system,

Patents, patent information, research and analysis the competition situation, as the patented competitive advantage, in order to in a dominant position in the competition and take comprehensive countermeasures. In biological pharmaceutical companies, patent has replaced equipment, plant, and so on to become the most valuable assets. In biological pharmaceutical intellectual property protection, the patent is the most effective way, are also at the heart of the biological medicine enterprise value evaluation index, only have a large number of high-quality patented technology, can form technology and market advantage, to ensure the sustainable development of the enterprise. In 2010, suzhou has established the first domestic biological medicine patent database, provide public services of intellectual property rights for bio-pharmaceutical enterprises. Predictably, along with the development of biopharmaceutical companies, the biological medicine patent database will be more and more in China. Patent strategy can be divided into basic strategic offensive and defensive strategy. Offensive strategy is refers to the enterprise by using the patent system to establish and expand their markets, defensive patent strategy refers to the enterprise by using the patent system to avoid losses. Biological pharmaceutical enterprise patent strategy can reduce the money and time, avoid repetition, more may adjust against rival patent to gain control of the market. Common patent strategy types are shown in table 2

\section{Tab 2 Common type of patent strategy}

Type Enterprise strength The competition strength goal
Attacking strong weak expand the market monopoly market
Defensive weak strong Protect the existing market
Follow up type Neck and neck No innovation, development and corresponding technology
mixed type Neck and neck According to the situation of competitors to adjust

Research and development of "outsourcing" is an important part of the new drug research and development, the reasons are due to the increased cost of r\&d. For spending cuts, biological medicine enterprises outside the ark can peel non-core part of the research and development, the countries in the research and development costs are relatively low. Now accept the research and development of "outsourcing" in China reached more than 2000 enterprises, the market share of up to $\$ 5.9$ billion, but the overall size is small, part of a powerful enterprise does not attach importance to "outsourcing" service, research and development of the whole "outsourcing" of output value proportion of the total output value of enterprises is not high also. While doing research and development "outsourcing" and the relationship between the independent innovation, to enhance independent innovation ability of the enterprise. Each new drug research and development need of high cost, long time, in order to shorten the development time, reduce development costs and deal with complex r\&d activity, is also actively application development pattern of "outsourcing". Biological pharmaceutical enterprise in our country the independent innovation ability is generally low, and with the help of a research and development of "outsourcing" opportunity, can learn to foreign advanced technology and management methods, to achieve the purpose of technological catch-up, technology transformation.

\section{References}

[1]Wang Y T Wuw L Wuw .I An Overview And Features Of Development Of Chinese 
Biophamaceutical Biotechnology [ J].Pham Biotechnol,2010 L17(1): 1-14.

[2]Smgg W.Facing The Financial Crisis The Phamaceutical Industry Development And Drug Innovation In China[ J]. Chin

Pham J201045(1): 1-4

[3] Hu X W, Chen H Rzhang Sr A View Ofbiophamaceutica1

Enterprises In The World[ J1.Chin MedBiotechnol 2009 4(2): 85-89.

[4] Zhangtm,SongA Z ,Wang F S,Advance Of Biochemical Drugs Research In China[J].Chin Pham J, 2009 44(20) : 1512-1525.

[5]Ibis World Industry Repor1t Biotechnology In Us Nn001[ R].Marc1l 11,2009.

[6] Ch P(2010)[S]2010

[7] Ruan L Advance Of Virus Vaccines Research In China[J].Bio- Technology\& Business, 2009 (3): 26-37.

[8] Yu Jr, Chen Dm ， Jiang Hb.The Trend Of Research In China[J].Biotechnology\& BusinessI 2009(1): 49-53. 